\title{
MEDIOS DE COMUNICACIÓN Y LA INFANCIA
}

\section{MEDIA AND CHILDREN}

\section{AUTORA}

\section{Miriam Alonso Bayón}

Universidad Europea Miguel de Cervantes (España)

nairim@hotmail.com

\section{RESUMEN}

Intentaremos determinar la influencia que tienen los medios de comunicación, especialmente la televisión, en los integrantes menores de las familias. Para ello estudiaremos en primer lugar el contexto: la sociedad en que vivimos, el proceso de socialización y de comunicación para así conocer la influencia que ejerce la televisión. Estudiaremos también la actuación de los padres, qué hacen y qué pueden hacer para crear un buen hábito de utilización del medio y, además, cómo deben acompañar durante la actividad para aclarar conceptos y evitar confusiones que desemboquen en una mala educación.

\section{PALABRAS CLAVE}

Infancia- Medios de comunicación - Televisión - Educación

\section{ABSTRACT}

Television can be a powerful entertainment and education tool for children given the right programming. However, studies have shown that television, and media in general, can also have a very negative influence. Learn about what the research shows regarding 
the influence of media on children, the dangers, and how to counteract the potential negative influence here on this page as we cover what parents need to know.

\section{KEY WORDS}

Childhood- Mass media - Television - Education

\section{ÍNDICE}

1. Definición de la sociedad de la información

\subsection{Definición de educación}

\subsection{Educación y televisión en la infancia y en la adolescencia}

2. La familia como agente de socialización

2.1 Funciones de los medios de comunicación

3. Bibliografía

\section{Definición de la sociedad de la información}

Isidro Fernández-Aballí Maspons, Consejero de Comunicación e Información en América Latina y el Caribe, de la UNESCO, define la sociedad de la información como:

"aquella comunidad que utiliza extensivamente y de forma optimizada las oportunidades que ofrecen las tecnologías de la información y las comunicaciones como medio para el desarrollo personal y profesional de todos sus ciudadanos."

(http://trabajaen.conaculta.gob.mx/convoca/anexos/inicio/Publicaciones paral nternet $3 / 20 \%$ 20Encuentro/ponencias/Completa.doc )

Nosotros podemos definir la sociedad de la información como aquella en la que se genera y se comparte información de forma continua, con la ayuda de las 
tecnologías que existen y de las que van apareciendo con el paso del tiempo. Por tanto, al asumir que vivimos en una sociedad que cumple estas características tenemos que decir que la comunicación, se produzca ésta al nivel que se produzca, es algo esencial en el día a día de las personas y como consecuencia crece la importancia para nosotros de los medios de comunicación, que están siempre presentes cumpliendo diferentes funciones que más adelante explicaremos.

Los medios de comunicación son la base de esta sociedad. Radio, prensa, televisión e Internet son los principales, aunque debemos mencionar también a la telefonía móvil, sobre todo a los móviles de última generación y que reúnen en un solo aparato al resto de medios (móviles con posibilidad de reproducir televisión y radio, conexión a Internet, cámara de fotos, etc.).

La dimensión de esta sociedad está creciendo tanto y tan rápidamente que los medios de comunicación tienden a mezclarse. El ejemplo más claro de esto es la prensa "on line", que aunque en nuestro país no tiene el mismo éxito que la prensa tradicional, cada vez son más las personas que visitan estas páginas web para buscar todo tipo de información.

\subsection{Definición de educación}

Según la Real Academia Española de la Lengua, el término "educación" significa "Crianza, enseñanza y doctrina que se da a los niños y a los jóvenes". Ésta es la acepción de la palabra que más se adecua a nuestra investigación. Entendemos que dicha enseñanza puede provenir de cualquier persona o personaje, pero de la misma forma damos por entendido el matiz positivo de la definición. Sabemos que al hablar de educar desechamos la posibilidad de maleducar, sin embargo, éste es el tema que nos ocupa ya que a veces sin intención se descuida la educación y de manera inmediata el menor comienza a asimilar conceptos que no son tan positivos como los que hubiera asimilado en caso de no haber existido el descuido. 
Al hablar de educación no solo hablamos de conocimientos, información, etc., sino que

"la educación implica favorecer el desarrollo integral de la persona partiendo de sus propias necesidades, apoyando su crecimiento físico y psíquico, permitiendo el ejercicio de todo un potencial de habilidades valiosas, sirviendo a una socialización que haga consciente al individuo de su papel en el mundo y de la necesidad de relacionarse con los demás desde la solidaridad, el respeto y la tolerancia." (García Matilla, 2003: 65).

La definición de Agustín García Matilla es más completa que la anterior y resalta la idea de que la educación no sólo es enseñanza de conocimientos, sino que consiste en formar a una persona para que actúe de forma válida o aceptable.

Concluimos el apartado de la definición de educación hablando del sujeto que lleva a cabo esta acción. Educación y padres son dos términos que parecen ir siempre unidos, sin embargo, no son sólo los padres los encargados de la educación de sus hijos, porque el niño de forma innata adquiere conductas de todos los que le rodean y tiende a la imitación, así, familiares, tutores, profesores, amigos y conocidos intervienen en el proceso. $Y$, por supuesto, los medios de comunicación también cumplen una función importantísima en los hogares. Suponen una fuente de información y reflejo de una realidad que será asimilada e imitada por los espectadores y de ahí la importancia de hacer un buen uso de los mismos siguiendo unas pautas determinadas, sobre todo en los momentos en los que la persona es más sensible e influenciable, como son la infancia y la adolescencia.

\subsection{Educación y televisión en la infancia y en la adolescencia}


Estadios evolutivos según Piaget:

\begin{tabular}{|c|l|l|}
\hline ESTADIOS & COMIENZO & ACTIVIDADES \\
\hline SENSORIOMOTOR & NACIMIENTO & $\begin{array}{l}\text { PERCEPCIÓN, RECONOCIMIENTO, } \\
\text { COORDINACIÓN DE MEDIOS Y FINES }\end{array}$ \\
\hline PREOPERATORIO & $1-2$ AÑOS & $\begin{array}{l}\text { COMPRENSIÓN DE LAS RELACIONES } \\
\text { FUNCIONALES, JUEGO SIMBÓLICO }\end{array}$ \\
\hline $\begin{array}{c}\text { OPERATORIO } \\
\text { CONCRETO }\end{array}$ & 6-7 AÑOS & $\begin{array}{l}\text { ESTRUCTURAS INVARIANTES DE CLASES, } \\
\text { RELACIONES Y NÚMEROS }\end{array}$ \\
\hline $\begin{array}{c}\text { OPERATORIO } \\
\text { FORMAL }\end{array}$ & 11-13 AÑOS & $\begin{array}{l}\text { PENSAMIENTO PROPOSICIONAL } \\
\text { UTILIZACIÓN DE HIPÓTESIS }\end{array}$ \\
\hline
\end{tabular}

Fuente: (García Matilla, 2003: 65)

En un principio, Piaget establece seis estadios evolutivos, sin embargo, resume la evolución del niño en cuatro, que son las representadas en el cuadro anterior. En cada etapa las necesidades del niño son diferentes y en relación con el tema que nos ocupa hay que señalar que la televisión está presente en todas y cada una de las etapas.

Tras el nacimiento, poco a poco, se desarrollarán las habilidades sensorio-motrices, el niño comienza a reconocer imágenes y sonidos independientemente del medio del que procedan. $Y$ sus acciones se empiezan a realizar siguiendo el esquema causaefecto.

Es obvio que la televisión no influye directamente en la educación, pero sí que lo hace, por ejemplo, mediante los sonidos que son reconocidos por el niño y que provocan una reacción en el mismo.

A los dos años, el niño se encuentra en el momento clave para el desarrollo de su inteligencia y al mismo tiempo se ve expuesto a la televisión, en parte por la 
curiosidad que siente por todo lo que le rodea. Además, se avanza en la utilización del lenguaje.

Entre los tres y los cuatro años, el niño ya es capaz de prestar atención por periodos cortos y empieza a desarrollar su imaginación y comienza el proceso de socialización. Encontramos aquí la primera etapa de la infancia en la que la televisión puede ser muy influyente y es importante que ésta no ejerza la función de "niñera" para que dicho medio no provoque daños educativos en el menor. Se reclama así la presencia de un adulto que le acompañe continuamente.

A partir de los cinco años, el tiempo dedicado a ver la televisión irá aumentado hasta llegar a la adolescencia, aproximadamente a los quince años, cuando la compañía de los amigos se impone como preferencia y el tiempo de visionado disminuye poco a poco.

La adolescencia es el siguiente estadio evolutivo, en nuestra cultura no podemos determinar el momento exacto del paso de infancia a adolescencia, porque no realizamos ningún rito que lo identifique; por tanto, debemos definir la adolescencia como una etapa de transición, de la infancia a la adultez, en la que tiene lugar gran parte del desarrollo físico, psicológico y social, y que, por tanto., lejos ser un mero intervalo temporal entre estas dos edades, constituye un proceso de recapitulación de toda la experiencia acumulada y de preparación para la vida adulta.

Por Piaget sabemos que el adolescente ya tiene capacidad para crear sus propias ideas y formas de pensar y además cree que éstas son las más acertadas. Al mismo tiempo necesita integrarse en la sociedad, en un conjunto de amigos y le gusta también verse rodeado por personas más adultas. En este momento, la televisión desempeña un papel muy importante, ya que los temas tratados en ella y los programas y series de moda serán algunos de los elementos que permitan al adolescente participar en las conversaciones del resto de adolescentes que le rodean 
y como consecuencia obtiene la satisfacción de sentirse admitido y valorado por el grupo, algo muy importante en este estadio.

Las ideas anteriores de Piaget son también recogidas en el Informe final del Grupo Mixto de trabajo M.E.C.-R.T.V.E. sobre radio y televisión educativa, y que fue editado en 1982. Reconoce la fuerte influencia de la televisión en los niños, pero apunta que esta influencia puede ser utilizada en el beneficio de ellos mismos siempre que la programación se diseñe con ese fin. (Informe, 1982: 152).

En nuestro país existió durante un tiempo el proyecto ideal de televisión educativa. En 1968 comenzó a emitir la denominada Televisión Escolar que consistía en la presentación de programas educativos en horario de 10 a 11 de la mañana y de lunes a viernes. Un año después, el Ministerio de Educación solicita que durante el periodo estival se dediquen espacios para ayudar a los alumnos de Bachillerato que hubieran suspendido sus exámenes de junio. "Cita para Septiembre" fue el título de dicho espacio que, a pesar de su éxito, no volvió a emitirse. En 1970, evaluado ya el triunfo de la programación educativa para escolares, se decide cambiar la idea y emitir programas para la educación de adultos. Comenzaron entonces los desacuerdos entre Televisión Española y el Ministerio de Educación, y los cambios en las parrillas de programación de la cadena. Todo ello supuso el fin de la programación educativa presentada como tal (/bid. 42). A partir de ese momento, el número de programas educativos emitidos ha sido muy reducido con ejemplos de éxito aislados, como Barrio Sésamo, un hecho que refleja el abandono de la audiencia infantil en las cadenas de televisión actuales. Las televisiones e instituciones son conscientes del problema existente por la falta de programación para audiencias como la infantil y la adolescente, sin embargo, sus preocupaciones no se ven finalmente reflejadas en las parrillas de programación.

Lolo Rico en su libro TV fábrica de mentiras nos habla sobre la programación infantil y juvenil y sobre su experiencia personal como guionista de este tipo de programas. 
Por una parte, refleja la influencia que dicho medio ejerce en los más pequeños introduciendo en sus cabezas experiencias innecesarias y deformativas a través de imágenes impactantes (Rico, 1992: 16). La televisión muestra homicidios, robos, secuestros, torturas, striptease...y los introduce en programas que los niños ven porque la gran mayoría de éstos ve programación adulta y además destacan entre sus preferencias las series de televisión, que son el máximo exponente de reproducción de este tipo de acciones que antes enumerábamos (/bid. 19). La autora establece que "ni la calidad de los contenidos ni la de la imagen deben separar lo adulto de lo infantil" (/bid. 203), lo que sí hay que tener en cuenta es el punto de vista desde el que se tratan los asuntos y evitar la densidad para no dificultar la comprensión. Esta es la fórmula que utilizó en la dirección de La Bola de Cristal y el éxito fue rotundo. Podemos deducir que no hace falta que la programación infantil se base en el dibujo animado, sino que lo necesario es que los contenidos y su forma de expresión se adecuen a este determinado público.

A lo largo de su libro, Lolo Rico manifiesta una postura negativa y pesimista ante la programación televisiva y la manipulación que supone en las mentes de los niños y adolescentes. Algo con lo que José Manuel Pérez Tornero está muy de acuerdo, lo que hace visible mediante expresiones como "La televisión es un perpetuo proceso de recomendación [...]. Un moldeamiento continuo e intensivo." También establece el proceso de identificación como la clave para la construcción del "telespectadormodelo" (Pérez Tornero, 1994: 122). Dicho proceso de identificación estará presente a lo largo de nuestro análisis y veremos que sí es determinante en la influencia que las series ejercen en los menores.

Para tratar de evitar, o por lo menos disminuir, estas consecuencias negativas de la televisión encontramos en el libro Televisión y Educación, de Joan Ferrés, algunas recomendaciones. Partimos de la base de que "Nuestra imagen de la realidad es básicamente la que nos ofrecen los media, y sobre todo la televisión." (Ferrés, 1994: 79). Por tanto, es muy importante la educación y conocimientos que adquieran los 
espectadores para poder reconocer la verdadera realidad. De tal forma que debemos conocer y hacer conocer los códigos que utiliza la televisión para disminuir el riesgo de la influencia negativa (/bid. 105). Es primordial insistir en la educación de los más pequeños para que aprendan a utilizar el medio y Joan Ferrés recoge esta idea diciendo que:

"Educar para la reflexión crítica supone [...], sobre todo, ser capaces de establecer relaciones coherentes y críticas entre lo que aparece en la pantalla y la realidad del mundo fuera de ella"( /bid. 106).

Conseguir este ideal de educación requiere de un proceso de constante ayuda e insistencia por parte de las diferentes figuras relevantes para el menor, pero este proceso de aprendizaje y educación lo desarrollamos de forma más detallada a continuación.

\section{La familia como agente de socialización}

La socialización es el proceso mediante el cual una persona adquiere los valores y normas necesarios para vivir acorde a una determinada sociedad. De esta forma, los individuos de una misma sociedad actuarán siguiendo unas pautas similares, evitando problemas en el seno de la misma. Al hablar del proceso de socialización, debemos hacer referencia a los agentes de socialización, que son los encargados de difundir estas normas, valores y conductas necesarias y constitutivas de una sociedad.

La familia es desde el momento en que nace un niño el agente de socialización por excelencia, sin embargo, a medida que las relaciones del niño se amplían, el espectro de agentes también lo hace y aparecen como tal los grupos de amigos, la escuela y sus profesores, la Iglesia o religión elegida, las instituciones gubernamentales y, sobre todo, los medios de comunicación. 
La televisión representa en parte la realidad de una sociedad, así el adolescente obtiene de ella modelos a seguir para integrarse en esa determinada sociedad. Por ejemplo, en televisión puede ver la tendencia de moda para cada temporada del año, a partir de ella puede elegir a sus ídolos que serán para él un ejemplo. En lo cultural, obtendrá información que le ayudará para poder conversar sobre cualquier tema de actualidad y para saber cuáles son las corrientes de opinión aceptadas y defendidas por la mayoría.

Éstos son algunos de los ejemplos que nos demuestran que el medio televisivo cobra gran fuerza como agente socializador y que también son recogidos de forma similar en libros como Televisión fábrica de mentiras de Lolo Rico o El niño y los medios de comunicación de P. Marks Greenfield. Además, debemos señalar que la televisión ejerce su función socializadora sobre todo a través de la ficción porque este género es más cercano para el espectador al crear éste de forma no intencionada relaciones de preferencia ante los personajes que aparecen en un determinado relato.

J effrey Arnett identifica cinco formas diferentes de utilización de los medios por parte de los adolescentes, y de cada una de ellas podemos deducir una manera distinta de socialización.

1. El uso como entretenimiento. Cuando no hay nada que hacer los adolescentes eligen la música y la televisión como medios de entretenimiento, si suponemos que la mayoría siguen este patrón encontramos aquí el primer punto de conexión entre dos personas diferentes que podrán intercambiar opiniones sobre algo que les ha unido.

2. El segundo uso se refiere a la formación de la identidad de género. En la televisión se ven reflejadas las diferentes posiciones y actividades que puede ocupar una persona dependiendo de si es hombre o mujer, esto no es 
una norma, sin embargo dentro de una sociedad los papeles de cada género están muy determinados y este medio refleja normalmente la situación real que se desarrolla en una comunidad. Así el espectador se crea unas expectativas u otras en relación con lo que observa.

3. La experimentación de sensaciones es la tercera posibilidad. Esto explica en muchas ocasiones la elección de los programas, series o películas que ve el individuo y para que le provoquen las sensaciones que en ese momento necesita o prefiere.

4. El cuarto uso viene motivado por la necesidad de escapismo que pueda tener una persona con problemas o preocupaciones. La televisión ayuda a evadirse por un tiempo de la realidad que te acompaña y a su vez ayuda a olvidar momentáneamente todo aquello que perturba la tranquilidad y estabilidad deseada.

5. La identificación con la cultura adolescente, el medio televisivo permite la sensación de conexión con el resto del grupo gracias al consumo de los mismos contenidos, que servirán posiblemente como tema de conversación.

José Ignacio Aguaded en su libro Convivir con la televisión incluye varias citas del autor Joan Ferrés, de las cuales destacamos dos: la primera, "buena parte de los efectos benéficos o nocivos que genera un medio dependen, no del medio en sí, sino del contexto de recepción de los mensajes"; y la segunda en que habla del valor del diálogo

"No basta con que el niño no esté solo físicamente ante la pantalla. Es preciso que no se sienta solo como telespectador, que comparta la experiencia, que pueda dialogar, confrontar." (Aguaded, 1999: 30 y 35). 
Joan Ferrés, en Televisión y educación, añade a estas citas infinitud de afirmaciones que remarcan la importancia de que el niño o adolescente no se encuentre solo ante contenidos que necesita que le sean explicados o simplemente comentados por un adulto que les aporte tranquilidad y seguridad con respecto a los conocimientos que está adquiriendo.

Observamos que la familia tiene un papel primordial en la educación y socialización del niño y por ello debe desempeñar también un papel importante a la hora de enseñarle a ver la televisión y los hábitos que debe seguir en relación con dicho medio comunicativo.

El hecho de que un niño pueda o no ver solo la televisión no depende de la edad, sino del grado de madurez y del tipo de programa que quiera ver. En cuanto al tiempo de visionado, una hora sería lo más adecuado (aunque se irá ampliando con el crecimiento), sin embargo, es necesario establecer un horario con principio y fin previo al comienzo del visionado y no ceder más tarde a ruegos manteniendo inmóvil esa decisión. El niño no debe tener una televisión en su habitación, porque de esta forma evitamos que dedique más tiempo a la televisión que a sus obligaciones y que se aísle del resto de la familia. En el caso de que el niño quisiera ver los denominados "programas basura", los padres o tutores deben ser firmes y negarse a que vean ese tipo de contenidos sin posibilidad de negociación.

Resumimos a continuación otras ideas contra el mal uso de la televisión: establecer un horario para levantarse y acostarse que no se modifique en ningún caso por el visionado de la televisión; ver la televisión en familia, el niño debe estar acompañado para que se le explique aquello que no pueda entender o que pueda malinterpretar; evitar que la televisión esté encendida durante las comidas para promover el diálogo; no utilizar continuamente el acto de no ver la televisión como castigo, porque esto ayudaría a la sobrevaloración del medio; evitar que haga los deberes con la televisión 
encendida; y por último, aunque igual de importante, dar ejemplo al niño para que vea que los adultos siguen las mismas pautas que imponen.

Observando estas últimas ideas descritas podríamos pensar que la televisión es un medio totalmente nocivo para los espectadores, sin embargo, esto no es así. Son los contenidos y el uso que nosotros hagamos de ellos los que hacen que el medio pueda perjudicar, sobre todo a los más pequeños, ya que éstos ven de forma indiscriminada cualquier programa que se emita y no tienen la capacidad de discernir lo bueno de lo malo.

La televisión es un medio informativo $\mathrm{y}$, por tanto, podemos aprovechar la información que nos transmite para potenciar valores en los menores. Si en un informativo emiten una noticia de una catástrofe nos puede servir para explicar las situaciones precarias que se viven en el mundo y fomentar la solidaridad. Es importante hacer entender a los menores que la misma información puede ser explicada de diferentes formas dependiendo del medio de comunicación que utilicemos para conocerlas y de la cadena, emisora o grupo editorial que la describa. El libro de estilo de cada medio de comunicación indica al periodista cómo debe tratar la información, pero además de este libro propio del medio, existen unas normas generales que los informadores deben acatar.

Alex Grijelmo, en El estilo del periodista, comenta que la opinión del periodista no tiene cabida en la noticia y si lo que busca es narrar su propia visión de los acontecimientos debe entonces utilizar un género periodístico diferente que advierta al espectador de que lo que escuchan no es información pura (Grijelmo, 1998: 49).

Entorno al tema de la opinión y de la objetividad se desarrolla un problema. Luisa Santamaría y María Jesús Casals hablan en su obra del ideal de objetividad y lo integran en un ideal más amplio, el de la verdad (Santamaría y Casals, 2000: 50). Un ideal, en ocasiones, difícil de cumplir, teniendo en cuenta que como dijo Aristóteles en Retórica y así lo recoge Parés i Maicas en Introducción a la comunicación social, el 
principal objetivo de la comunicación es el de persuadir e influir (Pares i Maicas, 1992: 92).

Por tanto, esta posible falta de objetividad es algo que todos, niños y mayores, debemos tener en cuenta para saber distinguir información de opinión y de esta forma, recopilar el mayor número de informaciones posibles para poder conformar la versión más aproximada a la realidad. El hábito de utilizar todas las posibilidades que ofrece un medio a través de sus diferentes canales de emisión es una costumbre que debe arraigarse desde pequeños, porque si la mente se acostumbra sólo a escuchar aquello que nos gusta, entonces el uso que estaremos haciendo del medio y la educación que recibirán los menores que nos rodeen no será la más adecuada, porque estará entonces, más que nunca, dirigida por los medios.

El estímulo de diálogos es otra de las maneras que la televisión puede ofrecer para educar. A partir de los contenidos que estamos viendo podemos iniciar una conversación que nos sirva para conocer el pensamiento del niño y para poder rectificar aquello en lo que se esté confundiendo. Además, estos mismos contenidos pueden servirnos para abordar temas problemáticos o difíciles de tratar fuera de contexto, nos referimos a temas como el sexo, los miedos, la muerte... Aprovechando también los contenidos podemos realizar de manera esporádica diferentes juegos que sirvan para potenciar la atención que el niño preste al programa que se esté viendo de tal forma que se evite el visionado pasivo que no sirva para un buen fin. Tras el visionado, podemos realizar preguntas sobre detalles de los personajes utilizando puntuaciones para averiguar el nivel de atención; podemos interrogar sobre el argumento para comprobar el nivel de comprensión y también podemos expresar opiniones individuales sobre los temas tratados en el episodio o programa visto.

Con relación al tipo de ejercicios que se pueden realizar para ayudar al niño a ver de una forma activa la televisión, en nuestra sociedad estamos acostumbrados a ver la televisión cuando llegamos a casa cansados de trabajar, es decir, como descanso, o 
mientras realizamos otra actividad, sin darnos cuenta de que con esta actitud estamos creando ejemplo en los menores que nos están viendo. Pero debemos señalar que los adultos tenemos ya formadas las estructuras atencionales, mientras que los niños están en medio del proceso de formación. Y para favorecer este tipo de visionado nos podemos servir de ejercicios del tipo de los descritos anteriormente.

\subsection{Funciones de los medios de comunicación}

Como exponen los hermanos Mattelart, la primera teoría sobre las funciones que cumplen los medios de comunicación fue formulada por Harold Laswell en 1948. En primer lugar, se establece como función la vigilancia del entorno, ya que los medios deben estar al tanto de todo lo que sucede para transmitir después a los receptores dicha información. La segunda función es la de correlación, análisis y evaluación de la información. Los medios buscan la información, pero como ya hemos explicado antes, cada uno la transmitirá de una manera diferente, de tal forma que aquello que transmita estará influido por su propia opinión. Por último, la función de socialización, que también hemos analizado. Los medios refuerzan los valores sociales, fomentan la cultura determinada del lugar de emisión y fortalecen las ideologías mayoritarias (Mattelart, 1997: 30).

A las antedichas funciones de Laswell, Paul F. Lazarsfeld y Robert K. Merton añadieron una cuarta, la función de diversión y entretenimiento. Los medios pueden funcionar como medio de alejamiento u olvido de problemas. Se pueden utilizar en el momento de descanso para relajarse, pero de esta función derivan algunos de los aspectos más negativos de los medios, ya que si actuamos como receptor pasivo, es decir, simplemente escuchamos, vemos y procesamos información de manera indiscriminada entonces estaremos siendo influidos de una forma exagerada y mucho más si el receptor es un menor (/bid. 31).

La televisión es actualmente el medio de comunicación más potente. Es más eficaz que otros medios porque transmite mediante imágenes y sonidos, y aunque hay 
otros medios que también lo hacen, la televisión es más accesible al tener presencia en todos los hogares, incluso con más de un televisor por vivienda.

Los niños ven la televisión incluso antes de saber leer y escribir y a los dieciocho años, como dice Anthony Giddens en su libro Sociología, habrán pasado más tiempo viendo la televisión que haciendo cualquier otra actividad, a excepción de dormir (Giddens, 2001: 575).

La televisión se ve, y como consecuencia puede entenderse de manera más o menos correcta independientemente del idioma o lugar donde estemos viéndola. La televisión es un cajón de sastre en el que tienen cabida infinidad de contenidos que podemos agrupar a grandes rasgos en: informativos y divulgativos. Sin embargo, ¿cuál es el nivel de calidad de estos contenidos?, ¿están bien repartidos los diferentes tipos de contenidos en las parrillas de televisión?, ¿todos los públicos encuentran lo que quieren en la televisión?...

\section{Bibliografía}

AGUADED GÓMEZ, José I gnacio (1999). Convivir con la televisión: familia, educación y recepción televisiva. Paidós. Barcelona.

AGUADERO, Francisco (1997). La sociedad de la información. Acento Editorial. Madrid.

Educación y medios de comunicación. Informe final del Grupo Mixto de trabajo M.E.C.-R.T.V.E. sobre Radio Televisión educativa. Ministerio de Educación y Ciencia. 1982.

FERRÉS, Joan (1994). Televisión y educación. Paidós. Barcelona.

FERRÉS, Joan (1997). Televisión subliminal. Socialización mediante comunicaciones inadvertidas. Paidós. Barcelona. 
GARCÍA MATILLA, Agustín (2003). Una televisión para la educación: la utopía posible.Gedisa. Barcelona.

GIDDENS, Anthony (2001). Sociología. 4ạ Edición. Alianza Editorial. Madrid.

GRIJ ELMO, Alex (1998). El estilo del periodista. Taurus, Madrid.

MARKS GREENFIELD, P (1998). El niño y los medios de comunicación. Los efectos de la televisión, videojuegos y ordenadores. Ediciones Morata. Madrid.

MATTELARD, Armand y Michèle (1997). Historia de las teorías de la comunicación. Paidós. Barcelona.

PARÉS I MAICAS, Manuel (1992). Introducción a la comunicación social. PPU. Barcelona.

PÉREZ TORNERO, José Manuel (1994). El desafío educativo de la televisión. Para comprender y usar el medio. Paidós. Barcelona.

RICO, Lolo (1992). TV fábrica de mentiras. La manipulación de nuestros hijos. Calpe. Madrid.

SANTAMARÍA SUÁREZ, Luisa y CASALS CARRO, María Jesús (2000). La opinión periodística. Argumentos y géneros para la persuasión. Fragua. Madrid. 